\title{
Introduction to the Special Section "Proxy Records and Mechanistic Studies of the Late Quaternary Paleoceanography of the Western Pacific Marginal Seas Using IMAGES Cores"
}

\author{
Meixun Zhao, Min-Te Chen, and Luc Beaufort
}

Citation: Zhao, M., M. T. Chen, and L. Beaufort, 2008: Introduction to the special section "Proxy records and mechanistic studies of the late quaternary paleoceanography of the western pacific marginal seas using IMAGES cores”. Terr. Atmos. Ocean. Sci., 19, I-III, doi: 10.3319/TAO.2008.19.4.I(IMAGES)

The western Pacific Ocean plays an important role in regulating and modulating the global climate system on interannual to geological timescales. Excellent records have been acquired by coring high sedimentation rate sites in the marginal seas of the western Pacific Ocean during IMAGES cruises. This special section has been proposed to publish papers presenting high-resolution records and the interpretation of climate change mechanisms revealed by these records.

Chen et al. (2008) established a long and detailed chronology (820 kyrs) for MD012380 from the Banda Sea by correlating their $\delta^{18} \mathrm{O}$ record for planktonic foraminifera Globigerinoides sacculifer with the astronomically tuned benthic $\delta^{18} \mathrm{O}$ record of MD972143. While spectral analysis confirms typical orbital forcing for the $\delta^{18} \mathrm{O}$ record $(100,41$, and 23 kyr cycles), cross-spectral analyses of the other proxy time series revealed different patterns separated by the MidBrunhes (MIS 13 - 10, 535 - $333 \mathrm{ka}$ ). The sediment coarse fraction and color (both are carbonate preservation proxies) both show relatively stronger powers at the 41-kyr band, and coherence among various proxies is relatively high, before the Mid-Brunhes. After the Mid-Brunhes, 100-kyr periodicity dominated both the $\delta^{18} \mathrm{O}$ and coarse fraction records but the coherence among the various proxies becomes weaker. Chen et al. (2008) concluded that the late Quaternary climate was fundamentally changed by the MidBrunhes event.

Monsoons have fundamental influences on the South China Sea (SCS) oceanography and paleoceanography (Wang et al. 2005). It has been generally accepted that the winter monsoon was stronger during the glacial stages and the summer monsoon has been stronger during the interglacial periods (Wang et al. 2005; Zhao et al. 2006a). However, the exact timing of these monsoon transitions and how they influenced the various aspects of the SCS paleoceanography are still not clear. The next four papers report data and discussions related to monsoon and productivity variabilities in the SCS. Shintani et al. (2008) report a new alkenone SST record of the last $28 \mathrm{kyr}$ for core MD972146 from the northern SCS. While the record reveals a typical SST pattern, the authors went further to reconstruct monsoon variability by using SST gradients between the southern and northern
SCS, and between the Sulu Sea and the northern SCS. The slow warming of the northern SCS compared with the southern SCS and the Sulu Sea resulted in a larger SST difference between the northern SCS and the adjacent tropical western Pacific region during the glaciation and the early Holocene. Shintani et al. (2008) concluded that this is caused by a stronger winter monsoon, in contrast with stalagmite records, which revealed increased summer monsoon precipitation since the Younger Dryas period (Wang et al. 2001). It is evident that more records and more novel approaches such as these are needed to resolve questions regarding the relationship and phases of the winter and summer monsoons. Yu et al. (2008) reported planktonic foraminiferal assemblage and SST records of the last $135 \mathrm{kyr}$ for core MD012394 from the Vietnam coastal upwelling area in the southwestern SCS, and they focused their discussion on summer monsoon variability. Using a Q-mode factor analysis of the fauna abundance data, Yu et al. (2008) found that the relative abundance of $G$. inflata (Factor 3) can be used as a summer monsoon proxy. High loadings of this summer proxy were recorded around 11, 33, 59, and $83 \mathrm{ka}$ when the local summer insolation was near the maximum. These intervals were coeval with lower SSTs, which suggest that core MD012394 SST variations were mostly controlled by summer monsoon induced upwelling. This hypothesis is further supported by the fact that SST variability was higher during MIS5 when the summer monsoon was stronger and more variable, and SST was less variable during the glacial when the summer monsoon was weaker. This provides a contrast with an alkenone record in which SST was more variable during the glacial (Zhao et al. 2006a). One explanation for these differences is that the alkenone index records annual SST; this index is less sensitive to summer monsoon variability. Longer (870 kyr) and multi-proxy records allow Shiau et al. (2008) to better evaluate both the summer and winter monsoon variabilities and phase relationship. They reported high resolution records for core MD972142 from the southeastern SCS, which include SST, productivity (TOC, opal and alkenone contents) and terrestrial components. The productivity records reveal some very interesting features. The TOC and the CPI (composite productivity index) records 
suggest higher total productivity during the glacials for the site, and this was suggested by the authors to be caused by a strengthened winter monsoon which brought more nutrients to the surface layers by mixing. On the other hand, opal content suggests higher productivity during the interglacials, which was linked with stronger summer monsoons and river inputs. However, it is not clear why the opal content was lower during the glacials. If one assumes that the opal content is purely a proxy for diatom productivity, then the results by Shiau et al. (2008) imply that there was a major phytoplankton community structure change for the site during glacial-interglacial cycles. It can be inferred from their data that diatom contribution to total productivity was lower during the glacials when the total productivity was higher, and its contribution was higher during the interglacials when total productivity was lower. This inference is in contrast with most published results, which suggest increased diatom contribution when productivity was higher (Werne et al. 2000), but is in agreement with the ODP 658C record from the sub-tropical NE Atlantic (Zhao et al. 2006b). The MD972142 results nicely demonstrate that more records using biomarkers as community structure proxies can help resolve some of these questions. Shiau et al. (2008) also observed a long-term increased trend in all productivity proxies since the mid-Brunhes. This, coupled with the MD012380 record from the Sulu Sea (Chen et al. 2008), suggests a change in the tropical western pacific, probably in response to the increased strength of the East Asian monsoon system.

Marine productivity changes in the past glacial to interglacial have been reconstructed by conventional proxies such as TOC, opal, and carbonate contents of sediments. Few attempts have been made in estimating paleo-productivity by more biologically-related indicators such as biomarkers. One group of biomarkers, the alkenones, have been used extensively to estimate SST by the degree of unstauration (the $\mathrm{U}_{\mathrm{k}}{ }^{37}$ ). In this special section, He et al. (2008) reported a more innovative approach by using a suite of biomarkers for estimating past changes in productivity and phytoplankton community structure in the northern SCS over the last glacial and Holocene. Their results reveal that productivity was much higher during the glacial for all major phytoplankton groups, and thus for total productivity. However, the community structure remained relatively stable, even though diatom contribution was slightly higher during the glacial, in contrast to the pattern in core MD 972142 in which diatom contribution was higher during the interglacials. Continuing these types of approach in western Pacific paleoceanography will shed light on how monsoons and other dominant climatic factors have controlled or responded to productivity changes as well as to phytoplankton community dynamics.

There is only one paper included here for the East China Sea. Chang et al. (2008) report high resolution planktic foraminifer fauna assemblage records of the last $40 \mathrm{kyr}$ for core MD012404 from the Okinawa Trough. Two features are particularly noticeable from these records. The first is that faunal data reveal abrupt changes at $\sim 16 \mathrm{ka}$, suggesting an early return to a warmer climate, most likely by the intrusion of the Kuroshio into the Okinawa Trough since the Last Glacial Maximum (LGM). The second is that the millennial-scale SST variations during the last glacial were wellcorrelated with the oxygen isotope oscillations in stalagmites from Hulu Cave and in the GISP 2 ice cores. Chang et al. (2008) hypothesized that these low SSTs and possibly low salinity (higher precipitation) events were coincident with strong East Asian winter monsoons, and were caused by millennial scale migrations of ITCZ in the past $40 \mathrm{kyr}$. While this is an interesting proposal, it remains to be tested with more records, as Holocene climate records from the terrestrial records of lower-latitude Asia indicate that the southward migration of the ITCZ resulted in colder but mostly drier climate (Staubwasser and Weiss 2006; Yancheva et al. 2007).

Wang and Wang (2008) studied the relative abundance of 13 diatom species in core MD012414 in order to reconstruct environmental and sea-ice conditions for the central Okhotsk Sea during the last 500 kyr. They were able to designate four types of environmental conditions for the Okhotsk Sea. The almost open-ocean, sea-ice free and typical interglacial assemblages were found in MIS 7 and MIS 3, while assemblages typical for perennial sea-ice cover conditions were found in Stages 6, 4, and 2. Interglacial Stages 9, 5 , and 1 are characterized by assemblages indicating conditions alternating between open-ocean and seasonal sea-ice cover. Surprisingly, the glacial MIS8 assemblage was dominated by warm and open ocean diatom species. These classifications have very important implications for the reconstruction of the history North Pacific Intermediate Water formation. Since seasonal sea ice formation is the key process driving the NPIW production, it could be inferred from this that the NPIW formation was stronger during the interglacial MIS 9, 5, and 1.

We hope that the seven papers assembled here demonstrate the range of proxies that can be used for western Pacific paleoceanographic reconstruction. The spatial and temporal variabilities of late Quaternary climate revealed by these records should help us to understand the mechanisms. We thank the authors for their contributions, the reviewers for their constructive comments, and the editors for considering this issue and their patience during the slow review process.

\section{REFERENCES}

Chang, Y. P., W. L. Wang, Y. Yokoyama, H. Matsuzaki, H. Kawahata, and M. T. Chen, 2008: Millennial-scale planktic foraminifer faunal variability in the East China 
Sea during the past 40000 years (IMAGES MD012404 from the Okinawa Trough). Terr. Atmos. Ocean. Sci., 19, 389-401, doi: 10.3319/TAO.2008.19.4.389(IMAGES).

Chen, C. W., K. Y. Wei, H. S. Mii, and T. N. Yang, 2008: A late quaternary planktonic foraminiferal oxygen isotope record of the Banda Sea: Chronostratigraphy, orbital forcing, and paleoceanographic implications. Terr. Atmos. Ocean. Sci., 19, 331-339, doi: 10.3319/TAO.2008.19.4.331(IMAGES).

He, J., M. Zhao, L. Li, H. Wang, and P. Wang, 2008: Biomarker evidence of relatively stable community structure in the Northern South China Sea during the last glacial and Holocene. Terr. Atmos. Ocean. Sci., 19, 377-387, doi: 10.3319/TAO.2008.19.4.377(IMAGES).

Shiau, L. J., P. S. Yu, K. Y. Wei, M. Yamamoto, T. Q. Lee, E. F. Yu, T. H. Fang, and M. T. Chen, 2008: Sea surface temperature, productivity, and terrestrial flux variations of the southeastern South China Sea over the past 800000 years (IMAGES MD972142). Terr. Atmos. Ocean. Sci., 19, 363-376, doi: 10.3319/TAO.2008.19.4.363(IMAGES).

Shintani, T., M. Yamamoto, and M. T. Chen, 2008: Slow warming of the northern South China Sea during the last deglaciation. Terr. Atmos. Ocean. Sci., 19, 341-346, doi: 10.3319/TAO.2008.19.4.341(IMAGES).

Staubwasser, M. and H. Weiss, 2006: Holocene climate and cultural evolution in late prehistoric-early historic West Asia Introduction. Quat. Res., 66, 372-387.

Wang, P., S. C. Clemens, L. Beaufort, P. Braconnot, G. Ganssen, Z. M. Jian, P. Kershaw, and M. Sarnthein, 2005: Evolution and variability of the Asian monsoon system: State of the art and outstanding issues. Quat. Sci. Rev., 24, 595-629.

Wang, W. L. and L. C. Wang, 2008: Reconstruction of oceanographic changes based on the diatom records of the central Okhotsk Sea over the last 500000 years. Terr. Atmos. Ocean. Sci., 19, 403-411, doi: 10.3319/TAO.2008.19.4. 403(IMAGES).

Wang, Y. J., H. Cheng, R. L. Edwards, Z. S. An, J. Y. Wu, C. C. Shen, and J. A. Dorale, 2001: A high-resolution absolute-dated Late Pleistocene monsoon record from Hulu Cave, China. Science, 294, 2345-2348.

Werne, J. P., D. J. Hollander, T. W. Lyons, and L. C. Peterson, 2000: Climate-induced variations in productivity and planktonic ecosystem structure from the Younger Dryas to Holocene in the Cariaco Basin, Venezuela. Paleoceanography, 15, 19-29.

Yancheva, G., N. R. Nowaczyk, J. Mingram, P. Dulski, G.
Schettler, J. F. W. Negendank, J. Q. Liu, D. M. Sigman, L. C. Peterson, and G. H. Haug, 2007: Influence of the intertropical convergence zone on the East Asian monsoon. Nature, 445, 74-77.

Yu, P. S., H. S. Mii, M. Murayama, and M. T. Chen, 2008: Late quaternary planktic foraminifer fauna and monsoon upwelling records from the western South China Sea, near the Vietnam margin (IMAGES MD012394). Terr. Atmos. Ocean. Sci., 19, 347-362, doi: 10.3319/TAO.2008.19. 4.347(IMAGES).

Zhao, M., C. Y. Huang, C. C. Wang, and G. J. Wei, 2006a: A millennial-scale $\mathrm{U}_{37}^{\mathrm{K}}$ sea-surface temperature record from the South China Sea ( 8 degrees N) over the last 150 kyr: Monsoon and sea-level influence. Palaeogeogr. Palaeoclimatol. Palaeoecol., 236, 39-55.

Zhao, M., J. L. Mercer, G. Eglinton, M. J. Higginson, and C. Y. Huang, 2006b: Comparative molecular biomarker assessment of phytoplankton paleoproductivity for the last 160 kyr off Cap Blanc, NW Africa. Org. Geochem., 37, 72-97.

\section{Responsible Editor:}

Chen-Feng You

Department of Earth Sciences, National Cheng Kung University

E-mail: cfy20@mail.ncku.edu.tw

\section{Guest Editors:}

Min-Te Chen

Institute of Applied Geosciences, National Taiwan Ocean University

E-mail: mtchen@mail.ntou.edu.tw

Luc Beaufort

CNRS-CEREGE, Aix-en-Provence Cedex 4, France

E-mail: beaufort@cerege.fr

\section{Executive Guest Editor:}

Meixun Zhao

Sate Key Laboratory of Marine Geology, School of Ocean and Earth Sciences, Tongji University

E-mail:maxzhao04@yahoo.com 